\title{
Agewise Outcome of Speech And Hearing In Prelingually Deaf Children After Cochlear Implantation
}

\author{
Dr. V.Saravanan.MS ${ }^{1}$,Dr. M.Nallasivam.MS ${ }^{2}$,Dr.M.Sivakumar. $\mathrm{MS}^{3}$ \\ ${ }^{1,2,3}$ (Department Of ENT, Coimbatore Medical College and Hospital, Coimbatore, Tamilnadu, India.)
}

\begin{abstract}
Objective: To assess the hearing and speech outcome of prelingually deaf children who underwent cochlear implantation over a period of 1 year.To evaluate the outcome of cochlear implantation in prelingually deaf children.To identify the ideal age for cochlear implantation in terms of best outcome.To assess the benefit of cochlear implantation in older children.

Materials and Methods: The study was carried out on 50 children who underwent cochlear implantation surgery at Coimbatore medical college hospital from July 2014 to June 2015. Speech and hearing was first assessed prior to the surgery. The children divided into two groups, $<3$ years of age of implantation and $3-6$ years at the time of implantation. The parameters recorded include Category of auditory perception, speech intelligibility rating scale, meaningful auditory integration scale and meaningful use of speech scale. First a pre op evaluation was done and then the parameters were recorded at 3 months, 6 months, and 12 month. The improvement was then compared based on the age of the child at implantation.

Results: Among the 50 patients 24 children were below 3 years and 26 children between $3-6$ years. And of the 50, 29 male and 21 female children were present. The average CAP score in the <3 year group was 5.17 \pm 0.702 and in the 3-6 year group it was $3.62 \pm 0.983$. The average SIR score of the <3 year group was $4.04 \pm$ 0.624 and in the $3-6$ year group was $2.23 \pm 0.863$. These observations were found to be statistically significant. The MAIS and MUSS grading and scoring of the children also showed highly significant difference between children implanted at age $<3$ years and between 3 - 6years with the earlier implanted children showing better response.

Conclusion: All children studied showed improvement in their hearing and speech abilities at the end of 1 year. The maximum benefit was seen in the younger age group ( $<3$ years at the time of implant) indicating a positive correlation between age and outcome in terms of clinical benefit. So it can be concluded that severe to profound hearing loss should be identified at the earliest in prelingually deaf children and considered for cochlear implantation in order to provide maximum benefit to the child.
\end{abstract}

Keywords: Cochlear implantation, Age at implantation, CAP score, SIR score, MAIS, MUSS.

\section{Introduction}

The introduction and advancements in cochlear implant surgery has brought about a remarkable shift in the management of sensorineural hearing loss. It has produced a great impact over a brief period of time. In less than half a century, it has evolved from the initial efforts to induce hearing by a direct electrical stimulation of the auditory nerve to the present situation where we are able to provide a viable solution in the form of a cochlear implant for auditory and speech rehabilitation for several deaf patients. The development of the cochlear implant was truly an interdisciplinary effort. Significant contributions ${ }^{21}$ were made by individuals belonging to various fields of medicine, engineering and physics.

\section{Materials And Methods}

A Prospective study was done among 50 bilaterally prelingually deaf children of age group 1 to 6 years with no benefit with hearing aid, who underwent cochlear implantation surgery at Government Medical College Hospital, Coimbatore from July 2014 to June 2015

\section{Inclusion Criteria}

All bilaterally prelingually deaf children of ages ranging from 1 year to 6 years under going cochlear implantation surgery at Government Medical College Hospital, Coimbatore.

\author{
Exclusion Criteria \\ 1. Postlingually deaf children \\ 2. Children with neurological defects \\ 3. Syndromic children \\ 4. Children with anatomic defects of the middle ear, inner ear or eighth nerve
}


5. Children already using hearing aids with benefit

\section{Methodology}

* Delayed onset of speech and lack of response to environmental sound stimuli is noticed by the parents or care takers of the prelingually deaf children and brought to the ENT outpatient department, or they are referred from peripheral hospitals.

* Such children undergo a preliminary audiological evaluation consisting of OAE and BERA to confirm the presence of bilateral severe to profound SNHL. The parents are then counseled regarding the prognosis of hearing in the child and about the need for cochlear implantation in such children.

* They then undergo a series of tests and investigations necessary for the preoperative evaluation of the audiological status as well as the general medical condition of the child and to rule out other anomalies in the child. These include:

\section{Audiological evaluations}

$>$ otoacoustic emission (OAE)

$>$ brainstem evoked response audiometry (BERA)

$>$ behavioral observational audiometry

$>$ hearing aid trial

$>$ impedance audiometry

\section{Imaging}

$>$ high resolution CT scan of the temporal bone with MRI of the inner ear

Other investigations

$>$ complete blood hemogram with bleeding time and clotting time

$>$ urine routine and microscopy

$>$ random blood sugar estimation

$>$ renal function test

$>\mathrm{ECG}$

$>$ Chest X ray

$>$ Echocardiography

* Pre operative psychological evaluation of the child is done to estimate the IQ of the child. Ophthalmologist, pediatrician, and cardiological consultations are done to rule out other anomalies and for the general medical fitness of the child to undergo surgery under general anaesthesia. The child is then sent for a pre anaesthetic check up by the anaesthesiologist.

\section{Surgery:}

* The ear to be operated is selected on the basis of audiological and imaging studies. The side with better residual hearing is preferred. From imaging studies any anatomical variation is noted, thickness of the cochlear nerve is estimated; the approachability to the facial recess and any difficulties like high riding jugular bulb or anterior lying sigmoid sinus can be predetermined.

- Surgery is done under general anaesthesia.

- Posterior tympanotomy is done and the middle ear entered in the region of facial recess.

- A Cochleostomy is done using skeeter drill and the scala tympani entered.

- Electrodes of the implant are advanced through the cochleostomy completely up to the hub. In cases with a normal anatomy of the cochlea with normal number of turns a Standard Med- El electrode of length $31 \mathrm{~mm}$ is used. In doubtful cases regarding the dimensions of the cochlea an insertion test device (ITD) is introduced initially to determine the length to be inserted and accordingly the appropriate electrode is chosen. Other electrodes available- medium length $24 \mathrm{~mm}$, short electrode- $15 \mathrm{~mm}$, flexsoft.

- After the electrode placement, with the help of the audiologist present, on table impedance audiometry, Electrical Stapedial Reflex Telemetry (ESRT), and Neural Response Telemetry (NRT) is done to ensure the proper placement and working of the device.

- The placement of the external device consisting of the microphone, speech processor and transmitter and the initial activation or "switching on" of the device is done 3 weeks after the surgery.

\section{Rehabilitation and training}

After the initial activation of the device, a training program is planned out for the child, incorporating both Ausplan and St. Gabriel's curriculum for training of pediatric population with cochlear implants. The 
number of classes is fixed over a one year period and days convenient for both the parents and therapist is chosen.

AUSPLAN is actually an abbreviation meaning Auditory, Speech, and Language. It consists of strategies laid down by qualified cochlear implant audiologists and speech therapists based at Children's Hospital Oakland. It is instrumental comprehending the tedious process of language development in children and by using it parents along with the therapist can establish the required time needed by the child to achieve targeted goals in terms of speech and language development. The children are categorized into three groups as A, B, or C depending on various criteria pre operative variables such as auditory program, age of implantation, total communication or oral communication, medical condition. They are then followed up for their results. There are three categories to be assessed including Auditory, Speech / Articulation, and Language, each of which has timeline specific targets that has to be achieved. The therapist and parent can categorize a child, and then based on the timeline specific goals know what the child is expected to achieve for example, at six months postimplant, twelve months post-implant etc. Teaching programs and exercises are listed for all three tracks, which the therapist as well as the parents should follow. Hence it is manual which helps to train a hearing impaired child to hear, speak, and converse fluently. It is a well inclusive program which comprises segments for auditory, speech and language objectives, all of which are essential for the development for proper communication skills in implanted children.

\section{Results}

1.The study was conducted to evaluate the difference in outcome of hearing and speech in prelingually deaf children after cochlear implantation, based on the age at which implantation is done and hence find out if earlier implantation is more beneficial to the child.

2.The present study was a prospective study.

3. Fifty children who underwent cochlear implant surgeries were divided into two groups based on the age at which they underwent the surgery, that is, less than 3years and $3-6$ years. Twenty four children $(48 \%)$ belonged to less than 3years group and 26 children (52\%) to $3-6$ years group. Out of these fifty children 29 $(58 \%)$ were male children and $21(42 \%)$ female. Comparison of scores of evaluation was done between the groups.

\begin{tabular}{|l|l|l|l|}
\hline Average scores & $<3$ years & $3-6$ years & $\mathrm{P}$ value \\
\hline Average CAP score & $5.17 \pm 0.702$ & $3.62 \pm 0.983$ & $\mathrm{P}<0.001$ \\
\hline Average SIR score & $4.04 \pm 0.624$ & $2.23 \pm 0.863$ & $\mathrm{P}<0.001$ \\
& & & \\
\hline Average MAIS score & $34.88 \pm 2.309$ & $27.38 \pm 6.268$ & $\mathrm{P}<0.001$ \\
\hline Average MUSS score & $32.79 \pm 2.604$ & $23.96 \pm 6.206$ & $\mathrm{P}<0.001$ \\
\hline
\end{tabular}

4.From the above analysis we can come to the following analysis. While observing the CAP score it is seen that there is an improvement in the CAP score in all children at the end of 1 year after implantation. Based on the observation from our study it is seen that the average CAP score in children implanted below 3 years is 5.17 with a standard deviation of \pm 0.702 whereas in case of the $3-6$ year age group it is $3.62 \pm 0.983$. The difference was statistically highly significant. So on an average child implanted before 3 years is able to "understand phrases without lip reading" whereas those implanted after 3 years are only able to "discriminate between speech sounds" at the end of 1 year after rehabilitation.

5.Based on the observation of the average SIR score it is seen that the average SIR score in those implanted at an age < 3 years is $4.04 \pm 0.624$ and in those implanted between the ages of 3 and 6 years is $2.23 \pm$ 0.863 . So it can be inferred that a children implanted before 3 years of age are able to produce speech which "is intelligible to a listener who has little experience of deaf persons speech and the listener need not concentrate unduly" whereas in those implanted between 3-6 years showed a SIR score corresponding to a speech "intelligible to listener who concentrates and lip reads within a known context" at the end of 1 year training program. The difference in terms of statistical analyses was highly significant.

6.The average Meaningful Auditory Integration Scale in children implanted before the age of 3 years was 34.88 with a standard deviation of \pm 2.309 and in children whose age at the time of implantation was $3-6$ years showed an average score of 27.38 with a standard deviation of \pm 6.268 . This was statistically highly significant.

7.The average Meaningful Use of Speech Scale was compared between the two groups and it was observed that the average value in the earlier implanted group in our study was $32.79 \pm 2.604$ and those who received implantation between $3-6$ years of age was $23.96 \pm 6.206$. The difference in observation is found to be highly significant.

8. When comparing the scores based on the gender groups average CAP score in males was found to be $4.38 \pm 1.293$ and in females it was $4.33 \pm 0.966$. The average SIR score in males was $3.17 \pm 1.284$ and in 
females it was $3 \pm 1.049$. The average MAIS was $31.55 \pm 5.429$ in males and $30.19 \pm 6.918$ in females. The average MUSS was $28 \pm 7.091$ in males and $28.48 \pm 5.836$ in females. The difference between these were found to be of no significance ( $\mathrm{p}$ value $>0.05$ ).

9.On comparing the present study to studies done by other researchers, it shows a correlation to the results obtained by Yang et $\mathbf{a l}^{\mathbf{3 2}}$, who compared the CAP and SIR score between 3 groups of children based on the age at the time of implantation; $1.3-2.9$ years ( 12 children), $3-4.9$ (17 children) and $5-7.9$ (26 children). It was shown that 1 year after implantation CAP and SIR score in the age group of 1.3 to 2.9 years was significantly higher than the other two groups. There was not much difference in the scores between $3-4.9$ and $5-7.9$ years groups.

10.In another study done by Tajudeen et $\mathbf{a l}^{\mathbf{3 4}}$ showed that children implanted at $6-12$ months of age showed at a significant better response compared to those implanted at 25- 36 months of age, and also performed better than those implanted between 13-24 months of age. Also the $13-24$ month group did much better than the $25-36$ months group. The comparisons were done at 3, 4, 5, and 6 years of age.

11.In a separate study done by Fang et $\mathbf{a l}^{\mathbf{3 3}}$, CAP and SIR scores were studied in children implanted before 5 years of age. It was shown that those implanted before 3 years of age had significantly better scoring than those who underwent implantation after 3 years of age.

\section{Limitations of the study}

$>$ Comparatively small sample size

$>$ Period of follow up was limited.

\section{Summary}

$>$ The present study was a prospective study which analyzed the correlation between the age of a child at the time of cochlear implantation surgery and the clinical outcome in terms of hearing and speech.

$>$ The study was conducted during one year period from July 2014 to June 2015 and it involved 50 children who had undergone cochlear implantation surgery at Coimbatore Medical College Hospital.

$>$ All children had undergone a thorough preoperative evaluation of general health and audiological parameters.

$>$ Post operatively the variables recorded during the follow up for the purpose of our study included Category of Auditory performance scale (CAP), Speech Intelligibility Rating scale (SIR), Meaningful Auditory Integration Scale (MAIS), and Meaningful Use of Speech Scale (MUSS). The children were evaluated on the basis of these scoring systems at the end of one year.

$>$ Among the 50 patients 24 children were below 3 years and 26 children between $3-6$ years. And of the 50, 29 male and 21 female children were present.

$>$ Maximum number of children (12) below 3 years at the time implantation showed a CAP score of 5 at the end of 1 year where as those between $3-6$ years at the time of implantation most (10) had a score of 3 . The average CAP score in the $<3$ year group was $5.17 \pm 0.702$ and in the $3-6$ year group it was 3.62 \pm 0.983 . The difference was found to be statistically significant.

$>$ In terms SIR score most (15) of children in the earlier age group obtained a score of 4 and in the older group the maximum patients (12) obtained a score of 2 . The average SIR score of the <3 year group was $4.04 \pm 0.624$ and in the $3-6$ year group was $2.23 \pm 0.863$. The difference was statistically highly significant.

$>$ The MAIS and MUSS grading and scoring of the children also showed highly significant difference between children implanted at age $<3$ years and between 3 -6years with the earlier implanted children showing better response.

$>$ Based on the gender of the child undergoing implantation the difference in the hearing and speech parameters between male and female children was found to be of no statistical significance ( $p$ value $>0.05$ ).

\section{Conclusion}

$>$ On the basis of the present study it was found that there is a definite improvement in the parameters used to assess hearing and speech at the end of 1 year, across all ages ranging from 1 to 6 years at the time of implantation.

$>$ It is observed that earlier the age of the child at time of implantation, better the response in the child in terms of hearing and speech.

$>$ It can be inferred from the study that there is a possibility of irreversible changes occurring in the auditory system with prolonged auditory deprivation in the prelingually deaf children which becomes a hindrance for the normal development of speech and language.

$>$ Hence children should be screened for hearing impairment to diagnose severe to profound hearing loss as early as possible and intervention in the form of cochlear implantation provided at the earliest for the best outcome. 


\section{Bibliography}

[1]. Nadal JBJr, Young YS, Glynn RJ. Survival of spiral ganglion cells in profound SNHL: implication of cochlear implant. Ann Otol Rhinol Laryngol 1989; 98: 411-416.

[2]. Miura M, Sando I, Hirsch BE, Onta Y. Analysis of spiral ganglion populationin children with normal and pathological ears. Ann Otol Rhinol Laryngol 2002; 111: 1059-1069.

[3]. Hardie NA, Shepherd RK. SNHL during development: morphological and physiological responseof cochlea and auditory brainstem. Hear Res 1999; 128: 147-165.

[4]. Waltzman SB, Cohel NL, Shapiro WH. Effects of chronic electrical stimulation on patients using a cochlear prosthesis. Otolaryngol Head Neck Surg 1991; 105: 797-801.

[5]. Woolsey CN, Walzl EM. Topical projection of nerve fibers from local region of cochlea to cerebral cortex. Bull Johns Hopkins Hosp 1942; 71:315-344

[6]. Blamey P, Arndt P, Bergeront F, et al. Factors affecting auditory performance of postlinguistically deaf adults using cochlear implant. Audiol Neurootol 1996; 1: 293-306.

[7]. Dowell RC, Clark GM, Seligman PM, Brown AM. Perception of connected speech without lip reading, using a multichannel hearing prosthesis. Acta Otolaryngol 1986; 102: 7-11.

[8]. McKay CM, McDermott HJ, Vandali AE, Clark GM. A comparison of speech perception of cochlear implantees using the Spectral Maximum Sound Processor and the MSP processor. Acta Otolaryngol 1992; 112: 752-761.

[9]. Cohen NL. Surgical techniques to avoid complications of cochlear implant in children. Adv Otorhinolaryngol 1997; 52: $161-163$.

[10]. Fishman AJ, Holliday RH. Principles of cochlear implant imaging. In: Waltzman SB, Cohen NL, eds. Cochlear implants. New York: Thieme, 2000: 79-107.

\begin{tabular}{|c|c|c|c|c|c|c|c|}
\hline \multicolumn{8}{|c|}{ Master Chart } \\
\hline sl no. & name & age & $\operatorname{sex}$ & CAP & SIR & MAIS & MUSS \\
\hline 1 & sruthi & $1 \mathrm{y} 11 \mathrm{~m}$ & female & 5 & 4 & 33 & 30 \\
\hline 2 & parthasarathy & $1 \mathrm{y} 11 \mathrm{~m}$ & male & 4 & 3 & 34 & 32 \\
\hline 3 & mukesh & $1 \mathrm{y} 11 \mathrm{~m}$ & male & 5 & 4 & 35 & 31 \\
\hline 4 & elavarasan & $1 \mathrm{y} 11 \mathrm{~m}$ & male & 5 & 4 & 37 & 36 \\
\hline 5 & diyash & $1 \mathrm{y} 9 \mathrm{~m}$ & male & 6 & 5 & 36 & 35 \\
\hline 6 & ramyadevi & $1 \mathrm{y} 9 \mathrm{~m}$ & female & 5 & 3 & 35 & 34 \\
\hline 7 & kavinraj & $2 y$ & male & 6 & 5 & 35 & 32 \\
\hline 8 & samsulreshma & $2 y$ & female & 6 & 4 & 35 & 37 \\
\hline 9 & hubaibafathima & $2 y$ & male & 5 & 4 & 37 & 32 \\
\hline 10 & meena & $2 y$ & female & 5 & 4 & 36 & 34 \\
\hline 11 & devasri & $2 \mathrm{y} 1 \mathrm{~m}$ & female & 4 & 4 & 35 & 32 \\
\hline 12 & yamini & $2 \mathrm{y} 1 \mathrm{~m}$ & female & 5 & 4 & 36 & 32 \\
\hline 13 & akash & $2 \mathrm{y} 11 \mathrm{~m}$ & male & 6 & 4 & 34 & 30 \\
\hline 14 & nandhabalan & $2 \mathrm{y} 11 \mathrm{~m}$ & male & 5 & 4 & 38 & 34 \\
\hline 15 & vishnu & $2 \mathrm{y} 11 \mathrm{~m}$ & male & 6 & 5 & 39 & 40 \\
\hline 16 & akil mohammed & $2 \mathrm{y} 4 \mathrm{~m}$ & male & 4 & 3 & 30 & 30 \\
\hline 17 & balakrishnan & $2 \mathrm{y} 6 \mathrm{~m}$ & male & 5 & 4 & 35 & 32 \\
\hline 18 & mohammed ilyas & $2 \mathrm{y} 6 \mathrm{~m}$ & male & 4 & 3 & 30 & 28 \\
\hline 19 & prabhakaran & $2 \mathrm{y} 6 \mathrm{~m}$ & male & 5 & 4 & 35 & 32 \\
\hline 20 & dikananth & $2 \mathrm{y} 6 \mathrm{~m}$ & male & 6 & 5 & 36 & 35 \\
\hline 21 & rajalakshmi & $2 \mathrm{y} 7 \mathrm{~m}$ & female & 6 & 5 & 37 & 34 \\
\hline 22 & kalaivanan & $2 \mathrm{y} 8 \mathrm{~m}$ & male & 5 & 4 & 34 & 31 \\
\hline 23 & anadakumar & $2 \mathrm{y} 8 \mathrm{~m}$ & male & 5 & 4 & 30 & 31 \\
\hline 24 & kavibharathi & $2 \mathrm{y} 8 \mathrm{~m}$ & male & 6 & 4 & 35 & 33 \\
\hline 25 & subash & $3 y 11 \mathrm{~m}$ & male & 4 & 2 & 21 & 24 \\
\hline 26 & srihariharan & $3 y 6 \mathrm{~m}$ & male & 3 & 2 & 21 & 18 \\
\hline 27 & muthugowtham & $4 y 1 \mathrm{~m}$ & female & 5 & 3 & 37 & 29 \\
\hline 28 & nandhini & $4 y 1 m$ & male & 3 & 2 & 20 & 30 \\
\hline 29 & poomarisri & $4 y 1 \mathrm{~m}$ & female & 4 & 3 & 33 & 25 \\
\hline
\end{tabular}




\begin{tabular}{|c|c|c|c|c|c|c|c|}
\hline 30 & pavithra & $4 \mathrm{y} 11 \mathrm{~m}$ & female & 3 & 2 & 24 & 22 \\
\hline 31 & santhanalakshmi & $4 \mathrm{y} 11 \mathrm{~m}$ & female & 4 & 2 & 27 & 19 \\
\hline 32 & poorani & $4 \mathrm{y} 11 \mathrm{~m}$ & female & 5 & 3 & 30 & 27 \\
\hline 33 & ummuhaniya & $4 y 3 m$ & female & 3 & 2 & 34 & 26 \\
\hline 34 & krithika & $4 y 3 \mathrm{~m}$ & female & 4 & 2 & 30 & 32 \\
\hline 35 & sivakumar & $4 y 8 m$ & male & 5 & 3 & 20 & 24 \\
\hline 36 & subhalaksmi & $4 y 8 m$ & female & 5 & 3 & 30 & 27 \\
\hline 37 & saravanasanthosh & $4 y 8 m$ & male & 4 & 1 & 34 & 20 \\
\hline 38 & kanishka & $5 \mathrm{y} 11 \mathrm{~m}$ & female & 4 & 4 & 27 & 28 \\
\hline 39 & dilip & $5 y 2 m$ & male & 3 & 1 & 28 & 18 \\
\hline 40 & hariharasudhan & $5 y 3 m$ & male & 3 & 4 & 34 & 34 \\
\hline 41 & loganathan & $5 \mathrm{y} 4 \mathrm{~m}$ & male & 3 & 2 & 24 & 20 \\
\hline 42 & sivaneshan & $5 y 5 m$ & male & 4 & 3 & 32 & 28 \\
\hline 43 & yuvanchakravarthy & $5 \mathrm{y} 5 \mathrm{~m}$ & male & 4 & 2 & 31 & 8 \\
\hline 44 & mohammed haq & $5 y 8 m$ & male & 1 & 1 & 28 & 19 \\
\hline 45 & swetha & $5 \mathrm{y} 9 \mathrm{~m}$ & female & 4 & 2 & 10 & 11 \\
\hline 46 & muthamilselvan & $5 \mathrm{y} 9 \mathrm{~m}$ & male & 3 & 2 & 30 & 28 \\
\hline 47 & sanjayram & $6 y$ & male & 2 & 1 & 22 & 20 \\
\hline 48 & lekhasree & $6 y$ & female & 5 & 3 & 35 & 28 \\
\hline 49 & renugadevi & $6 y$ & female & 3 & 2 & 30 & 28 \\
\hline 50 & tharasri & $6 y$ & female & 3 & 1 & 20 & 30 \\
\hline
\end{tabular}

